\title{
Determinants of University Dropout: A Case of Thailand
}

\author{
Kelzang Tentsho ${ }^{1}$, Rhysa McNeil ${ }^{1,2}, \&$ Phattrawan Tongkumchum ${ }^{1}$ \\ ${ }^{1}$ Faculty of Science and Technology, Prince of Songkla University, Pattani, Thailand \\ ${ }^{2}$ Centre of Excellence in Mathematics, Commission on Higher Education (CHE), Ministry of Education, \\ Ratchathewi, Bangkok, Thailand \\ Correspondence: Rhysa McNeil, Faculty of Science and Technology, Prince of Songkla University, Pattani, \\ Thailand. Tel: 66-87-288-2646. E-mail: nittaya.ch@psu.ac.th
}

Received: April 27, 2019

doi:10.5539/ass.v15n7p49
Accepted: May 11, 2019 Online Published: June 30, 2019

URL: https://doi.org/10.5539/ass.v15n7p49

\begin{abstract}
Student dropout is a growing concern for educational institutions across the world and extensive research on this issue has been done in past few decades. In this study, we analyzed the determinants of student propensity to dropout at Prince of Songkla University, Pattani campus. The data comprised 10,377 students enrolled between the 2007 and 2011 academic years. Variables included in the analysis were admission year, faculty, gender-religion, first semester GPA and admission type. The overall dropout rate over the five-year period was $23.9 \%$, and a decreasing trend in dropout rate was found from second semester and onwards. A logistic regression model was used to determine the effect of explanatory variables on dropout. The findings indicate that admission year, gender-religion, faculty and first semester GPA are strongly associated with student dropout.
\end{abstract}

Keywords: student dropout, first semester GPA, sum contrasts, Logistic regression model

\section{Introduction}

Student attrition is a growing concern for higher educational institutions across the world and the issue of student attrition is becoming a central focus of study in higher education (Tinto, 2006). One of the main goals of any university is to produce as many graduates as possible (Tinto, 2015), however, maintaining the right balance of students enrolled and graduated has become a challenge for educational institutions for the past few decades. According to Larsen, Sommersel, and Larsen (2013), university dropout is defined as a situation where students leave the university in which they have enrolled before obtaining a formal degree. Student dropout is categorized as voluntary (leaving university for reasons such as health issues, financial and personal) and involuntary (academic failure). For the purpose of this study, dropout is described as student withdrawal from the college either voluntarily or involuntarily.

Extensive research on student dropout has been done using Tinto's (1975) Student Integration Theory. This theoretical model argues that student dropout is a longitudinal process of interactions between the individual and the social and academic system, and that an individual comfortable with their social life and academic performance is less likely to dropout. Pascarella and Terenzini (1980) examined various dimensions of student integration model and report that departure from college is influenced by the quality of peer interaction for females, and the level of institutional and goal commitments for males. Bennett's (2003) model of students' decision to quit from university study argues that students with low self-confidence are more likely withdraw when coupled with learning and financial difficulties

Tinto (2015) describes student persistence as motivation which is often influenced by student experiences in college. The nature of college experiences, which is viewed as an outcome of the interaction among student goals, self-efficacy, sense of belonging and perception towards the curriculum, can either enhance or diminish student motivation. Without motivation persistence is unlikely. Student attrition is also temporal in nature, and dropout process is time dependent. Students undergo three major stages-separation (disassociating from their previous community), transition (passage between old and new environment) and incorporation (integrating into new environment) to successfully graduate from college. Students experience varying degrees of challenges while navigating through these stages, and those unable to cope with the challenges withdraw from the college (Tinto, 1988). Prior research findings suggest that the process of student dropout differs with each year in college. A range of personal and institutional factors tend to affect first year attrition, while personal factors have strong 
influence in second year attrition (Willcoxson, 2010).

In literature, variables such as social, institutional, economic, psychoeducational and evolutionary factors are responsible for higher dropout rates (Arce, Crespo, \& Miguez-Alvarez, 2015). Student enrolling into a wrong field of study was identified as one of the causes of dropout (Davies \& Elias, 2003; Christie, Munro, \& Fisher, 2004). The varying dropout rate across faculties (Araque, Roldan, \& Salguero, 2009; Paura \& Arhipova, 2014; Chies, Graziosi, \& Pauli, 2014; Sittichai, Tongkumchum, \& McNeil, 2008) corroborates the influence of faculty on dropout. There is an evidence of the influence of student demographic characteristics on student departure. The dropout probability is lower for females (Fortin, Lessard, \& Marcotte, 2010; Salazar, Lopera Gomez, \& Mario, 2012). Dropout rates have also been reported to differ by racial class (Smith \& Naylor, 2001; Synco, 2012). Low academic achievement is another prevalent characteristic among dropouts across all the racial groups. Numerous authors are of the opinion that grade point average (GPA) is one of the significant predictors of student dropout (Bennett, 2003; Synco, 2012; Chies et al., 2014; Yi et al., 2015). Prior research suggests that the type of admission to college also affects student dropout. Students enrolled through special programs have a higher probability to dropout compared to those enrolled through other types of admissions (Salazar et al., 2012). Largely, dropout is also influenced by the combination of financial, social and institutional difficulties faced by the students (Glogowska, Young, \& Lockyer, 2007).

Most of the factors related to student dropout stems from North America and European literature. Very few such studies exist in Thai context (Sittichai, Tongkumchum, \& McNeil, 2009; Sittichai, 2012) and the conclusions drawn from Western studies cannot be generalized to Asian higher institutions. For instance, the dropout rate at public university in southern Thailand between 1999 and 2006 was found to be 20.3\% (Sittichai et al., 2009). The same study reported strong association between dropout and factors such as year of admission, faculty, and gender-religion. While these findings are important, this study is different in couple of ways. First, we investigate the influence of first semester GPA on the propensity to student dropout which is not the part of analysis in previous studies. Second, we look at the influence of admission type on student withdrawal and persistence. There is also a lack of accurate estimates of dropout rates in faculties established after 2002, and the rates reported in previous studies may not represent the overall dropout rate for the same university.

It is essential for universities to estimate student attrition rates, identify and understand underlying factors that shape student's decision to leave university. It is equally important to understand dropout process as time dependent and examine at what point of the university career students are more vulnerable to dropout. In doing so, it would enable concerned stakeholders to identify factors directly related to institution and accordingly implement response strategies to address the multidimensional issue of student dropout. Therefore, this study aims to estimate the prevalence of dropouts between 2007 and 2011, and also to examine the factors associated with dropout at a public university in Southern Thailand.

\section{Materials and Methods}

\subsection{Data and Variables}

Data obtained from the registrar office, Prince of Songkla University, Pattani Campus was used in this study. The data consisted of 10,377 full-time students enrolled in seven faculties between 2007 and 2011. The data contains information such as gender, religion, semester grade point average, faculty, student status and time of withdrawal from university.

The outcome of interest was defined as a dichotomous variable based on whether a student terminated their enrollment (dropout) or successfully continued to their graduation (non-dropout), and coded as "1" and " 0 " respectively. Students dropping out for ill health or death were excluded from the analysis. The five explanatory variables considered were admission year (5 categories), faculty (7 categories), gender-religion (4 categories), first-semester GPA (3 categories) and type of admission (3 categories). Gender and religion were combined into four levels in order to provide more detailed demographic information of dropouts. First semester GPA (recorded on the scale of 0.0-4.0) is converted into categorical variable with three levels. The first category is a GPA less than 2.0, which is the academic requirement for the freshmen at this university to stay enrolled in the program. The other two levels are: '2.0-2.99' and '3.0-4.0'.

In Thailand, students are admitted to universities through various admission tracks. Generally, universities in Thailand use the centralized admission system, and students admitted through such type are categorized as 'centralized admission system'. Students admitted to college by taking tests conducted by particular university are categorized as 'direct admission system'. Finally, students admitted through special admission programs such as scholarships and other form of grants are categorized as 'others'. 


\subsection{Logistic Regression Model}

Logistic regression is used to predict a dichotomous outcome (Sittichai et al., 2009; Araque et al., 2009; Salazar et al., 2012; Synco, 2012). The logistic regression equation is

$$
\log \left(\frac{p_{i}}{1-p_{1}}\right)=\alpha+\sum_{i=1}^{k} \beta_{i} x_{1}
$$

where $p_{i}$ is the expected probability of a positive outcome, $\alpha$ is the intercept, $\beta_{i}$ are the regression coefficients, and $x_{i}$ are explanatory variables. The odds ratio (OR), which is a comparative measure of two odds relative to different events, is calculated by taking the exponential of the regression coefficients $\left(e^{\beta_{i}}\right)$.

The overall fit of the model is evaluated with the likelihood ratio test (LRT), where the fit of two models, that is, models with and without the explanatory variables are compared. The test compares the model deviance without explanatory variables (null model) to the model deviance with $k$ explanatory variables. The difference in deviances gives a goodness of fit statistic $G$, and has an approximate $\chi^{2}$ distribution with $k$ degrees of freedom. The formula for the $G$ statistic is

$$
G=\chi^{2}=-2 \log \frac{\text { likelihood of null model }}{\text { likelihood of model with } k \text { predictors }}
$$

If the statistic is significant $(\mathrm{p}<0.05)$, it indicates that the model with $k$ explanatory variables provide a better fit to the data. Similarly, a likelihood ratio test is also used to evaluate the contribution of individual variables to the model (Park, 2013).

After implementing the model, the difference of each explanatory variable is compared to the overall dropout rate by computing $95 \%$ confidence intervals. The adjusted proportion and the confidence intervals for student dropout are computed using weighted sum contrasts (Tongkumchum \& McNeil, 2009). The statistical analysis was performed using R (R Core Team, 2015).

\section{Results}

A total of 10,377 students were enrolled in seven faculties between 2007 and 2011. The Faculty of Humanities and Social Sciences had the largest number of students enrolled with 3,058 (29.5\%) followed by the Faculty of Education with 2,918 (28.1\%). The majority of students were from the female-Muslim gender-religion group with 6,431 (62.0\%). Regarding type of admission, 4,759 (45.9\%) students were admitted through the direct admission system, $3,784(36.5 \%)$ through the centralized admission system, and 1,834 (17.7\%) through other tracks.

With respect to pattern of student dropout, there was a decreasing trend in annual dropout rate over the five-year period. The highest dropout rate was found in 2007 (29.0\%) and the lowest in 2011 (16.9\%). Dropout rates varied across faculties. The Faculty of Science and Technology experienced the highest dropout rate at $48.2 \%$ followed by the Faculty of Fine and Applied Arts (46.6\%). The Faculty of Education had the lowest dropout rate at $12.4 \%$. Among the gender-religion groups, the dropout rate was highest among the male-Others group (38.2\%) followed by male-Muslim (31.7\%), and lowest in the female-Muslim group (19.6\%). Likewise, the rate was significantly higher among those with first semester GPA less than 2.00 . The dropout rates among all admission types were higher than $20 \%$. The overall dropout rate over the 5 -year period was $23.9 \%$ (Table 1 ).

Students were followed up till $15^{\text {th }}$ semester of their university study from the initial enrollment. This is because not all the students complete their studies within the stipulated time. Of the total dropouts $(2,489), 32.3 \%(806$ out of 2,489) of the students have left university during second semester, and first year dropout rate amounts to $56.1 \%(1,397$ out of 2,489). However, a decreasing pattern of dropout rate was observed from second semester through $15^{\text {th }}$ semester (Figure 1).

Table 1. Distribution of students by explanatory variables and dropout rate

\begin{tabular}{lccc}
\hline \multicolumn{1}{c}{ Characteristic } & Total Students $(N=10,377)$ & Total Dropouts $(N=2,489)$ & Dropout Rate (\%) \\
\hline Admission Year & & & \\
2007 & 1,915 & 556 & 29.0 \\
2008 & 2,114 & 581 & 27.5 \\
2009 & 2,148 & 539 & 25.1 \\
2010 & 2,007 & 442 & 22.0 \\
\hline
\end{tabular}




\begin{tabular}{|c|c|c|c|}
\hline 2011 & 2,193 & 371 & 16.9 \\
\hline \multicolumn{4}{|l|}{ Faculty } \\
\hline Education & 2,918 & 361 & 12.4 \\
\hline Islamic Studies & 1,201 & 200 & 16.7 \\
\hline Political Science & 1,036 & 217 & 20.9 \\
\hline Humanities and Social Sciences & 3,058 & 806 & 26.4 \\
\hline Communication Sciences & 880 & 288 & 32.7 \\
\hline Fine and Applied Arts & 118 & 55 & 46.6 \\
\hline Science and Technology & 1,166 & 562 & 48.2 \\
\hline \multicolumn{4}{|l|}{ Gender-Religion } \\
\hline Female-Muslim & 6,431 & 1,259 & 19.6 \\
\hline Female-Others & 1,301 & 356 & 27.4 \\
\hline Male-Muslim & 2,101 & 666 & 31.7 \\
\hline Male-Others & 544 & 208 & 38.2 \\
\hline \multicolumn{4}{|l|}{ First semester GPA } \\
\hline Less than 2.00 & 2,148 & 1,822 & 45.9 \\
\hline $2.00-2.99$ & 4,267 & 583 & 12.0 \\
\hline 3.00 and above & 1,473 & 86 & 5.5 \\
\hline \multicolumn{4}{|l|}{ Type of Admission } \\
\hline Direct system & 4,759 & 1,146 & 24.1 \\
\hline Centralized system & 3,784 & 947 & 25.0 \\
\hline Other & 1,834 & 396 & 21.6 \\
\hline
\end{tabular}

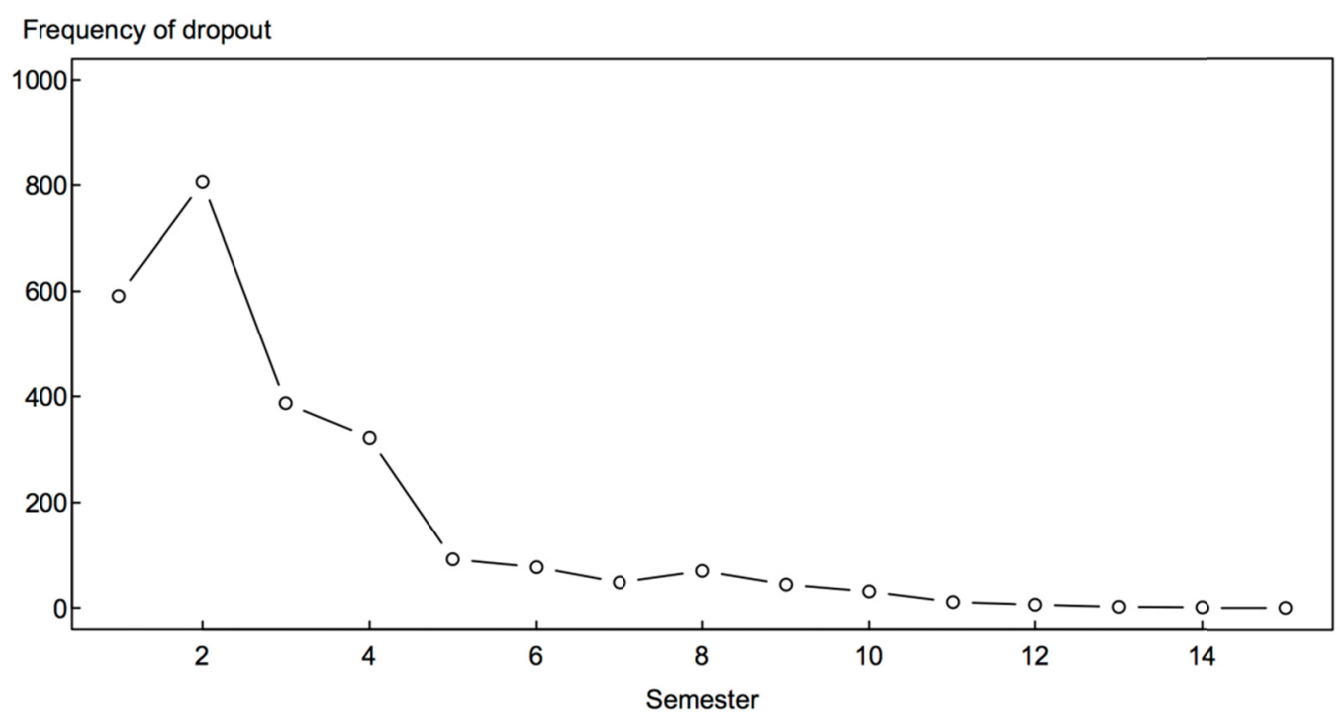

Figure 1. Frequency of student dropout by semester

Logistic regression model (Equation 1) was fitted to data to determine the significance of each explanatory variable on predicting the interest of outcome. We combined the Faculty of Science and Technology and the Faculty of Fine and Applied Arts resulting to six levels for the faculty variable. This was done due to the fact that they had similar dropout rates and small proportion of students enrolling into the Faculty of Fine and Applied Arts. Variables for the final model were selected using a backward elimination method. Of the five explanatory variables considered, admission year, faculty, gender-religion and first-semester GPA remained significant at the $5 \%$ significance level $(\mathrm{p}<0.05)$. A model consisting of only significant explanatory variables was compared to the full model (with all the explanatory variables included). The likelihood ratio test statistic $(G=1.95)$ was compared with the critical value of a $\chi^{2}$ distribution with $k=1$ degree of freedom $(\mathrm{p}=0.38)$. The large $\mathrm{p}$-value indicates that the variable 'type of admission' does not contribute much to the model in predicting outcome. 
After implementing the model, the overall significance of the model was evaluated. The likelihood ratio test statistic $(G=2170.9)$ was compared to critical value of a $\chi^{2}$ distribution with $k=4$ degrees of freedom $(\mathrm{p}<$ $0.001)$. The small $p$-value indicates that four explanatory variables taken together are significant and independent predictors of student dropout.

Figure 2 shows a plot of crude and adjusted dropout rates for each of the explanatory variables. The overall dropout rate was $23.9 \%$, represented by the horizontal line. The adjusted dropout rate (20.8\%, CI: $19.11-22.51)$ for admission year 2011 was significantly lower than the overall dropout rate. The adjusted dropout rates for the Faculty of Humanities and Social Sciences (28.5\%, CI: 26.97 - 30.14), Faculty of Communication Sciences (29.1\%, CI: 26.02 - 32.29) and Faculty of Science and Technology/Fine and Applied Arts (35.2\%, CI: 32.53 $37.90)$ were significantly higher than the overall dropout rate. However, the Faculty of Education (14.6\%, CI: $13.46-15.80)$ and the Faculty of Islamic Studies (21.0\%, CI: 18.53 - 23.68) both had adjusted dropout rates lower than the overall dropout rate. The adjusted dropout rate was significantly higher in the male-Muslim (30.2\%, CI: 28.23 - 32.28) and male-Others (34.7\%, CI: 30.36 - 39.22) groups and lower in the female-Muslim group (20.6\%, CI: 19.94 - 21.24). Finally, the adjusted dropout rate among students with lower first semester GPA was higher, and among those with higher first semester GPA was lower than the overall dropout rate.

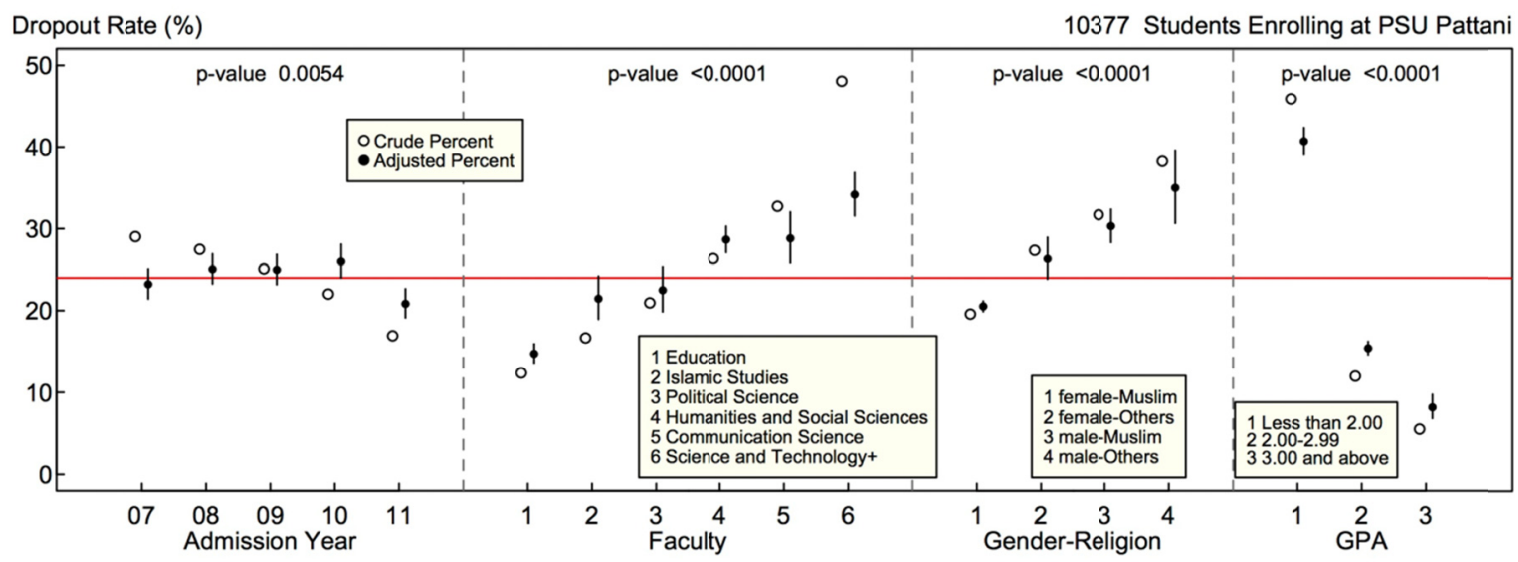

Figure 2. Crude percent and adjusted percent with $95 \%$ confidence intervals of dropouts by explanatory variables

\section{Discussions}

The overall dropout rate (23.9\%) in this study was higher than that observed in previous studies. Sittichai et al. (2008) noted that due to changes in student demographic characteristics, dropout rates were higher for students enrolling after 2001. Congruent with previous study, the odds to student dropout is higher in first and second semester (Salazar et al., 2012). The varying dropout rates across faculties could be attributed to, as noted by Davies and Elias (2003) and Sittichai (2012), students enrolling into non-preferred fields of study. This finding is consistent with previous studies (Paura \& Arhipova, 2014; Chies et al., 2014). Another possible reason could be the differences in the reputation of the program enrolled. Students' are less likely to leave if their degree program has higher reputation to the outside world (Bennett, 2003). In a study by Sittichai et al. (2009), the highest dropout rate was found in the Faculty of Science and Technology. Higher dropout rates were found among students studying difficult science subjects such as; mathematics, engineering and physical sciences (Johnes \& McNabb, 2004).

The current research findings in regard to demographic characteristics are also consistent with prior studies. Low dropout rates among females could be explained by the fact that females consider graduation from university as an important factor to succeed in life (Ivan, Pricopie, Frunzaru, Cismaru, \& Corbu, 2012). According to Aina (2013), women are more willing to invest in higher education because of poor labour markets for women, and to avoid discrimination in the labour market. In addition, relatively low student attendances and high dropout rates for both males and females from other religious background could be explained by the political unrest in southern Thailand. Due to security concerns, Pattani campus is not a preferred university for students from other parts of Thailand, and even those who are enrolled are likely to transfer to another university (Sittichai, 2012).

A high dropout rate is usually found among students with low GPA. An academically successful first-semester GPA has considerable influence on a student's decision to continue or withdraw from university. This is because 
GPA confirms student's level of ability with respect to the program enrolled within a semester of study (Montmarquette, Mahseredjian, \& Houle, 2001). There is also an evidence of academically weak students being more vulnerable to dropout (Chies et al., 2014; Yi et al., 2015) and students who decide to drop out usually have low GPA (Guimaraes et al., 2010). An empirical study by Synco (2012) on student dropout claims that an increase of one point in cumulative GPA increases the likelihood of student returning in the subsequent academic years. Dropouts even stated academic difficulties as one of the reasons for their decision to leave university and their academic failure may be attributed to wrong choice of course (Davies \& Elias, 2003). One of the possible explanations for students not doing well academically in the first semester is due to university's standard of subject contents. Students are required to study all the core subjects (such as Mathematics, Physics, English, etc.) as freshmen and at the same time cope with other aspects of university life. In doing so, academically weak students might have a difficult time maintaining their grades, consequently causing their grade point average to suffer (Sittichai, 2012).

Our finding, that similar dropout rates among students using different admission types, however, is not consistent with other studies (Salazar et al., 2012; O'Neill, Christensen et al., 2014), in which dropout rates varied for students admitted through various admission methods. Prince of Songkla University (PSU), the first public university in southern Thailand, is a preferred destination for students from southern-border provinces because of its location and relatively low student fees compared to universities in other parts of Thailand. Students also have confidence in the quality of instruction and programs offered by the university (Churngchow \& Sinprajukpol, 2016). In addition, since the majority of the students come from nearby areas, they might still be living with their family, which provides them a favorable emotional environment and a well-adjusted lifestyle. For these reasons, one may speculate that their decision to dropout is not influenced by admission type.

This study presents some limitations. First, the sample for this study comes from a single institution; thus, the findings cannot be generalized to other populations. Second, we only considered students who dropped out of PSU, Pattani campus disregarding other forms of dropout such as change of faculty and transferal to another university. Further studies are required to consider inclusion of this and other factors such as the parental background and socio-economic status of students to assess their influence on dropout rates.

\section{Conclusion and Policy Implications}

Our results showed a significant decrease in student dropout rates from 2007 to 2011 . The student enrollment was still dominated by Muslim (74.5\%) and female (82.0\%). Students enrolled in the Faculty of Science and Technology and Faculty of Fine and Applied Arts had the highest dropout rates. Demographic student characteristics and semester GPA were also significantly associated with dropout. However, type of admission had no effect on dropout. The rate of dropout was modeled as a function of set of explanatory variables and, the model diagnostic test statistics indicated that our model provided an acceptable fit to the data.

The findings from this study have implications for institutional policy, specifically to the university management to improve retention rates. Our analysis reveals that one out of four students is likely to leave university prematurely. Considering the diverse student population, strategic programs should be identified and implemented with both the faculties and students, and discuss the multifaceted challenges of student attrition. Students are often overwhelmed by the faculty approachability upon entering college, and those who struggle academically during first year tend to interact more with faculty members (Hurtado, et al., 2011). Therefore, it is imperative that adequate cues regarding approachability are made accessible to promote student-faculty interaction. We suggest faculties to underline programs to encourage students to partake in classroom discussions, promote conducive learning environment, employ active learning teaching approaches and engage students in academic activities. Likewise, it is also critical to maintain the right balance between rigor and support. Since the quality of pre-college preparation vary among freshmen, those who attended low performing high school might struggle to cope with conceptual demands required at the university level courses. This indicates the need to optimize preparation of the choice of study at early stages of university career.

On the basis of evidence, students with first semester GPA less than 2.0 to be considered as being more at risk to dropout, and accordingly emphasize on retention initiatives. It indicates the need of response strategies and evaluation policies to assess the impact of various retention programs. This is in line with Tinto's (1988) argument that any forms of action from the institution should be focused on the early stages of student's university career as majority of the students depart in the first year of study. The literature tells us that academic performance and social integration influence students' decision to stay or quit. Implementation of extended orientation programs aimed to help student integrate to university culture, the provision of remedial/coaching classes for academically poor students, course structure, additional student support services, and assisting in 
developing positive study habits might also help improve their academic performance, and consequently reduce attrition rates.

Another possible intervention could be implementation of first-year seminar as it enhances student social and academic integration during the first year of college (Al-Sheeb et al., 2018). The impact of such program on student engagement, awareness, and general attitudes towards higher education would benefit university administrations in curbing dropout cases.

\section{Acknowledgements}

We are immensely grateful to Emeritus Professor Don McNeil for his guidance. We would also like to thank registrar office, PSU, Pattani campus for providing us data for this study, and thank to the Centre of Excellence in Mathematics, Commission on Higher Education, Thailand, for providing support for this research.

\section{References}

Aina, C. (2013). Parental background and university dropout in Italy. Higher Education, 65(4), 437-456. https://doi.org/10.1007/s10734-012-9554-z

Al-Sheeb, B. A., Abdulwahed, M. S., \& Hamouda, A. M. (2018). Impact of first-year seminar on student engagement, awareness, and general attitudes towards higher education. Journal of Applied Research in Higher Education, 10(1), 15-30. https://doi.org/10.1108/JARHE-01-2017-0006

Araque, F., Roldan, C., \& Salguero, A. (2009). Factors influencing university drop out rates. Computers and Education, 53(3), 563-574. https://doi.org/10.1016/j.compedu.2009.03.013

Arce, M. E., Crespo, B., \& Miguez-Alvarez, C. (2015). Higher Education Drop-out in Spain- Particular case of Universities in Galicia. Inter. Education Studies, 8(5), 247-264. https://doi.org/10.5539/ies.v8n5p247

Bennett, R. (2003). Determinants of undergraduate student drop out rates in a university Business Studies Department. J. of Further \& Higher Edu., 27(2), 123-141. https://doi.org/10.1080/030987703200065154

Chies, L., Graziosi, G., \& Pauli, F. (2014). Job opportunities and academic dropout: The case of the University of Trieste. Procedia Economics \& Finance, 17(14), 63-70. https://doi.org/10.1016/S2212-5671(14)00879-X

Christie, H., Munro, M., \& Fisher, M. (2004). Leaving university early: Exploring the differences between continuing and non-continuing students. Studies in Higher Education, 29(5), 617-636. https://doi.org/10.1080/0307507042000261580

Churngchow, C., \& Sinprajukpol, W. (2016). Factors affecting the scholastic achievement of Prince of Songkla University students from private schools with Islam instruction in the three southern border provinces. Kasetsart Journal of Social Sciences, 37(1), 59-65. https://doi.org/10.1016/j.kjss.2016.01.001

Davies, R., \& Elias, P. (2003). Dropping out: A study of early leavers from higher education (Research Report RR386). London: Department for Education and Skills.

Fortin, L., Lessard, A., \& Marcotte, D. (2010). Comparison by gender of students with behavior problems who dropped out of school. Procedia - Social and Behavioral Sciences, 2(2), 5530-5538. https://doi.org/10.1016/j.sbspro.2010.03.902

Glogowska, M., Young, P., \& Lockyer, L. (2007). Should I go or should I stay?: A study of factors influencing students' decisions on early leaving. Active Learning in Higher Education, 8(1), 63-77. https://doi.org/10.1177/1469787407074115

Guimarães, J., Sampaio, B., \& Sampaio, Y. (2010). What is behind University Dropout Decision in Brazil? A Bivariate Probability Model. The Empirical Economics Letters, 9(1), 601-608.

Hurtado, S., Eagan, M. K., Tran, M. C., Newman, C. B., Chang, M. J., \& Velasco, P. (2011). "We do Science Here": Underrepresented students' interactions with faculty in different college contexts. Journal of Social Issues, 67(3), 553-579. https://doi.org/10.1111/j.1540-4560.2011.01714.x

Ivan, L., Pricopie, R., Frunzaru, V., Cismaru, D., \& Corbu, N. (2012). The Risk of Dropping Education for Romanian High School Students. Structural Factors and Educational Policies. Procedia - Social and Behavioral Sciences, 46, 2312-2321. https://doi.org/10.1016/j.sbspro.2012.05.477

Johnes, G., \& McNabb, R. (2004). Never give up on the good times: student attrition in the UK. Oxford Bulletin of Economics and Statistics, 66(1), 23-47. https://doi.org/10.1111/j.1468-0084.2004.00068.x

Johnes, J., \& Taylor, J. (1989). Undergraduate non-completion rates: Differences between UK universities. Higher Education, 18(2), 209-225. https://doi.org/10.1007/BF00139181 
Larsen, M. R., Sommersel, H. B., \& Larsen, M. S. (2013). Evidence on Dropout Phenomena at Universities. Copenhagen: Aarhus University. Retrieved from http:/edu.au.dk/fileadmin/edu/Udgivelser/Clearinghouse/ Review/Evidence_on_dropout_from_universities_brief_version.pdf

Montmarquette, C., Mahseredjian, S., \& Houle, R. (2001). The determinants of university dropouts: A bivariate probability model with sample selection. Economics of Education Review, 20(5), 475-484. https://doi.org/10.1016/S0272-7757(00)00029-7

O'Neill, L. D., Christensen, M. K., Vonsild, M. C., \& Wallstedt, B. (2014). Program specific admission testing and dropout for sports science students: A prospective cohort study. Dansk Universitetspaedagogisk Tidsskrift, 9(17), 55-70.

Park, H. (2013). An introduction to logistic regression: From basic concepts to interpretation with particular attention to nursing domain. Journal of Korean Academy of Nursing, 43(2), 154-164. https://doi.org/10.4040/jkan.2013.43.2.154

Pascarella, T. E., \& Terenzini, T. P. (1980). Predicting freshman persistence and voluntary dropout decisions from a theoretical model. Journal of Higher Education, 51(1), 60-75. https://doi.org/10.2307/1981125

Paura, L., \& Arhipova, I. (2014). Cause analysis of students' Dropout Rate in Higher Education Study Program. Procedia - Social and Behavioral Sciences, 109, 1282-1286. https://doi.org/10.1016/j.sbspro.2013.12.625

R Core Team. (2015). R: A language and environment for statistical computing. R Foundation for Statistical Computing, Vienna, Austria. URL http://www.R-project.org/

Salazar, U. J. C., Lopera Gómez, C. M., \& Mario César, J. E. (2012). Identification of factors that affect the loss of student status using A Logit Survival Model for Discrete Time Data. Dyna, 79(171), 16-22. Retrieved from https://search.proquest.com/docview/1677480406?accountid=28431

Sittichai, R. (2012). Why are there dropouts among university students? Experiences in a Thai university. Inter. Journal of Educational Development, 32(2), 283-289. https://doi.org/10.1016/j.ijedudev.2011.04.010

Sittichai, R., Tongkumchum, P., \& McNeil, N. (2008). Discontinuation among University Students in Pattani. Songklanakarin Journal of Social Sciences and Humanities, 14(3), 399-408.

Sittichai, R., Tongkumchum, P., \& McNeil, N. (2009). Discontinuation among University Students in Southern Thailand. International Education Studies, 2(2), 17-21. https://doi.org/10.5539/ies.v2n2p17

Smith, J., \& Naylor, R. (2001). Determinants of degree performance in UK universities: A statistical analysis of the 1993 student cohort. Oxford Bulletin of Economics and Statistics, 63(1), 29-59. https://doi.org/10.1111/1468-0084.00208

Synco, T. M. (2012). Background or experience? Using logistic regression to predict college retention (Doctoral dissertation, University of Alabama). Retrieved from http://www.mhsl.uab.edu/dt/2012p/synco.pdf

Tinto, V. (1975). Dropout from Higher Education: A Theoretical Synthesis of Recent Research. Review of Educational Research, 45(1), 89-125. https://doi.org/10.2307/1170024

Tinto, V. (1980). Stages of Student Departure: Reflections on the longitudinal character of student leaving. The Journal of Higher Education, 59(4), 438-455. https://doi.org/10.2307/1981920

Tinto, V. (2006). Rsearch and practice of student retention: What next? Journal of College Student Retention, 8(1), 1-19. https://doi.org/10.2190/C0C4-EFT9-EG7W-PWP4

Tinto, V. (2015). Through the eyes of students. Journal of College Student Retention: Research, Theory \& Practice, 19(3), 254-269. https://doi.org/10.1177/1521025115621917

Tongkumchum, P., \& McNeil, D. (2009). Confidence intervals using contrasts for regression model. Songklanakarin Journal of Science and Technology, 31(2), 151-156.

Yi, H., Zhang, L., Yao, Y., Wang, A., Ma, Y., Shi, Y., ... Rozelle, S. (2015). Exploring the dropout rates and causes of dropout in upper-secondary technical and vocational education and training (TVET) schools in China. Inter. J. of Educational Development, 42, 115-123. https://doi.org/10.1016/j.ijedudev.2015.04.009

\section{Copyrights}

Copyright for this article is retained by the author(s), with first publication rights granted to the journal.

This is an open-access article distributed under the terms and conditions of the Creative Commons Attribution license (http://creativecommons.org/licenses/by/4.0/). 